\title{
Inelastic behavior of reinforced concrete cantilever beam with embedded steel truss in flexural plastic hinge under cyclic loading
}

\author{
Fatmawati Amir ${ }^{1,2^{*}}$, Iman Satyarno ${ }^{1 *}$, Djoko Sulistyo ${ }^{1}$ \\ ${ }^{1}$ Department of Civil and Environmental Engineering, Faculty of Engineering, Universitas Gadjah Mada, 55284 Yogyakarta, Indonesia \\ ${ }^{2}$ Department of Civil Engineering, Faculty of Engineering, Universitas Tadulako, 94118 Palu, Indonesia
}

\begin{abstract}
Structures are expected to have ductile behavior under major earthquakes. One requirement to achieve this ductile behavior is when the structures have no shear failures in their elements. This paper discusses a new method by using the embedded steel truss in the flexural plastic hinges of beam to avoid shear failure. As already known that the shear strength provided by the concrete will be decreased when the ductility of flexural plastic hinges develop in a member. Therefore, a conservative procedure by ignoring the role of concrete in flexural plastic hinges in resisting the shear demand is adopted by some codes. This will increase the demand for shear reinforcement provided by the stirrup or transverse reinforcement in the plastic hinge; yet it still does not ensure that the shear failure does not come to happen. From the laboratory test results under cyclic loading in this study, it can be noted that the beam with embedded steel truss in the plastic hinge has better hysteretic behavior than the one without the embedded steel truss. The evaluation of test result is also shown the strength of the beam with the embedded steel truss in the plastic hinge is not reduced with an increase in the amplitude of the drift of 1.4 to 3.5. Besides, the strength of the beam without embedded steel truss in the plastic hinge is reduced with an increase in the amplitude of the drift after reaching 2.5 .
\end{abstract}

\section{Introduction}

\subsection{Background}

Regarding high intensity earthquake, the performance of a critical region will be controlled by detailing and amount of the reinforcement. Significant degradation of strength and stiffness in the performances of inelastic displacement will be undergone because of the insufficient reinforcement. The critical zones location of the beam is generally near the faces of the columns and/or along the span. The location of critical zones is greatly determined by the combination of the seismic action, gravity load application, and the reinforcement detailing and curtailment. The shear strength of beams depends on the level of the imposed ductility when plastic hinging occurs close to the joint. Meanwhile, the mechanism that initiates by flexural plastic hinges may be reduced as the ductility demand increases into plastic hinges with shear failure (NZSEE, 2006). Shear strength degradation may worsen the capacity of lateral force in the frame [2].

The shear strength degradation in plastic hinge zones is due to the nominal shear stress reduction, $V_{c}$ that is resisted by the mechanisms of concrete. The nominal shear stress that can be resisted is decreased with the increase in flexural ductility due to a cyclic loading. The flexural ductility increases because of the shear strength degradation in plastic hinge regions, the initial cracks should occur in the reinforced concrete beam section and it should spread immediately and than it results in the beam shear failure. As seen in Figure 1, $k$ is a symbol of shear strength degradation value and it is equal to 0.20 in $v_{c}$ calculation (or $\mathrm{k}=0.17$ by Indonesian Standard for Building Design, SNI 2847:2013) [2, 3].

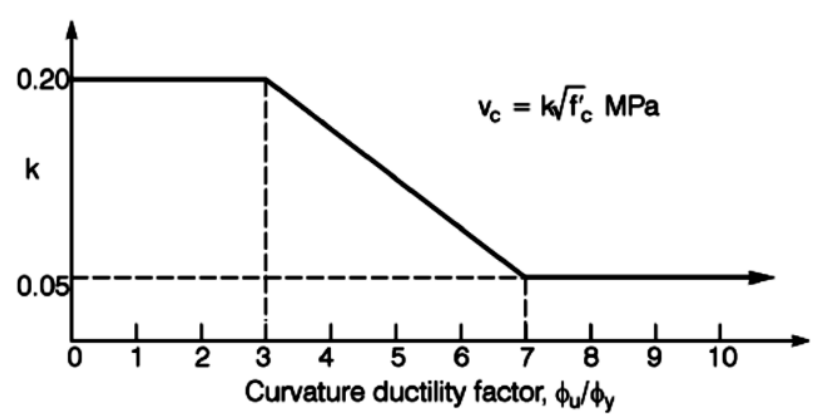

Fig. 1. The nominal shear strength degradation resisted by the concrete with imposed cyclic curvature ductility factor (NZSEE, 2006) [2].

This paper discusses a new method of using embedded steel truss in the flexural plastic hinges of the beam to avoid shear failure. As shown in Figure 1, the shear strength provided by the concrete will be decreased as the flexural plastic hinges develop in a member. Therefore, a conservative procedure by ignoring the role of concrete in flexural plastic hinges in resisting the shear demand is adopted by some codes. This will increase the demand for shear reinforcement provided by the stirrup or transverse reinforcement in the plastic hinge; yet, it still does not ensure that shear failure does not come to happen. The embeddedment of steel truss in reinforced concrete is adopted to preserve the shear strength provided by the concrete for raising the energy dissipation capacity and the ductility of conventional reinforced concrete elements. In this study, an experimental investigation on two cantilever beams with and without steel truss was coducted to analyze the shear behavior of the proposed beams in terms of modes of failure, strength, stiffness,

\footnotetext{
* Corresponding author: fatmastructureuntad@gmail.com; fatmawati.amir@mail.ugm.ac.id
} 
ductility and the capacity of energy absorption. For this purpose, a cyclic test procedure for the reinforced concrete cantilever beam with and without embedded steel truss was performed to reproduce the beam critical areas demands. This test procedure includes the history of displacement by getting started from the effects of the lateral load where failure takes place or when the specified drift limits are exceeded.

\subsection{Literature review}

A successful design for reinforced concrete member due to seismic action is a thing that can detain the shear capacity until it reaches the required ductility and the capacity of deformation. The design for seismic shear is generally based on a truss model and an empirical equation from laboratory testing $[9,12]$. Priestley et al. (1994) provided an interesting method to portend the shear-resisting mechanisms behavior, with consideration of the columns element ductility under load reversals. For beams, it should be significant because the presence of axial loads in the columns enhances the mechanism of shear resisted by the concrete [12].

There are various studies on shear design in the plastic hinge member to reduce the shear degradation due to the flexural plastic hinge development in the reinforced concrete members. The results of these studies showed that the stiffness and the shear strength were decreased progressively in the reinforced concrete, although the number and the diameter of the transverse reinforcement could be ensured sufficient and it confined concrete core capabilities to resist the shear under load reversals. It indicates that the configuration of transverse reinforcement unlikely reduces the shear degradation due to an increase in flexural ductility of the reinforced concrete members $[5,7,8,9]$. The alternative for the shear design that has been analyzed in reducing the reinforced concrete structures flexural ductility is the additional steel profiles for reinforced concrete/concrete encased steel shape. The results of the experimental study showed that the composite concrete encased steel shape had an excellent strength and ductility if it restrained in the core of concrete around the steel profile, particularly in the flexural plastic hinge areas. Otherwise, the significant horizontal cracks still occur in the interface of concrete and steel flange and it is known as shear splitting failure due to cyclic loading $([10,11],[13-15])$.

\section{Basic theory}

\subsection{Shear design of reinforced concrete beam according to SNI 2847:2013}

Base on Indonesian Standard for Building Design, SNI 2847:2013, the cross sections design for the reinforced concrete element related to shear shall be calculated by the following equation [3]:

$$
\varphi V_{n} \geq V_{u}
$$

Where the transverse reinforcement that is perpendicular to the axis of the member shall be calculated as follows,

$$
V s=\frac{A_{v} f_{y t} d}{s}
$$

$A_{v}$ is the transverse reinforcement area within spacing $s$, $V_{u}$ is the shear strength in the section considered and $V_{n}$ is the nominal shear strength and and they are calculated as follows :

$$
V_{n}=V_{c}+V_{s}
$$

While $V_{c}$ is the nominal shear strength provided by the concrete beam and it is calculated by using this formula below.

$$
V_{c}=0.17 \lambda \sqrt{f_{c}^{\prime}} b_{w} d
$$

Where $f_{c}^{\prime}, b_{w}$ and $d$ are the compressive strength of concrete, the width of the beam section and the effective height of the beam section, respectively.

For beams of special moment frames that form a part of the seismic resistance structure to resist flexure and shear. The first transverse reinforcement shall not located more than $50 \mathrm{~mm}$ from the face of a supporting column. The spacing of the transverse reinforcements should be adjusted and it should not exceed the following criteria [3]:

(a) $0.25 \mathrm{~d}$

(b) Six times the diameter of the smallest primary flexural reinforcing bars

(c) $150 \mathrm{~mm}$.

Where transverse reinforcements are not required, the transverse reinforcements with seismic hooks at both ends shall be spaced at a distance not more than $\mathrm{d} / 2$ throughout the length of the beam.

According to SNI 2847:2013 section 21.5.4.2 for the shear strength provided by transverse reinforcement, it should be designed to resist the shear by assuming $V_{c}=0$, and making the requirement for transverse reinforcement increases. To decrease the requirement of transverse reinforcement and to defend the concrete strength capability, a new structure was proposed for the beam by embedding two steel trusses in the flexural plastic hinge region.

\subsection{The design of shear for reinforced concrete cantilever beam with embedded steel truss in the flexural plastic hinge zone}

Based on the truss analogy, the design of shear for the reinforced concrete beam with embedded two steel trusses in flexural plastic hinge area of the beam was investigated under load reversals. In this design, the shear strength value, $V_{u}$ provided by the concrete, $V_{c}$ (Equation 4), transverse reinforcement, $V_{s}$ (Equation 2) and diagonal steel bar, $V_{d}$ as below [6]:

$$
V_{u}=V_{c}+V_{s}+V_{d}
$$


Where $V_{d}$, was calculated based on Figure 2 as follows.

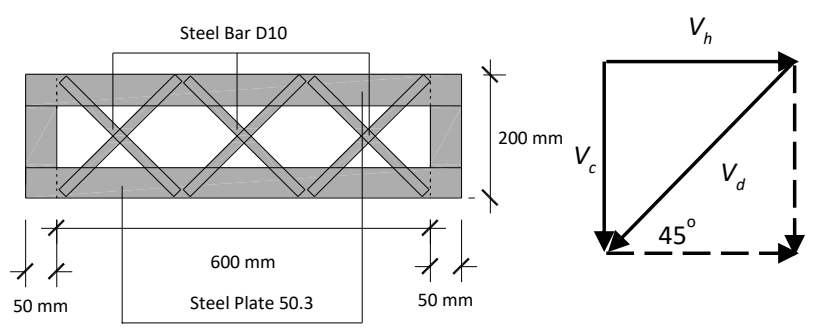

Fig. 2. The shear design of steel truss

According to Figure 2, the steel truss consists of some diagonal components as diagonal bars and the horizontal components as steel plate. The design of the steel truss should be calculated using the following equation.

$$
\begin{gathered}
V_{d}=\frac{V_{c}}{\sin 45}=A_{d} f_{y} \\
A_{d}=\frac{V_{c}}{\sin 45 f_{y}}
\end{gathered}
$$

Where, $V_{d}$ : shear strength provided by the diagonal bar $(\mathrm{kN})$

$A_{d}=0.25 \pi D^{2}\left(\mathrm{~mm}^{2}\right)$

$D$ : diagonal bar diameter $(\mathrm{mm})$

The shear strength provided by the steel plate of steel truss (Equation 8) is represented in the following equation.

$$
\begin{gathered}
V_{h}=V_{c}=A_{h} f_{y} \\
V_{d}=\frac{V_{c}}{f_{y}}
\end{gathered}
$$

Where, $\quad V_{h}$ : Shear provided by steel plate $(\mathrm{kN})$

$A_{h}=b t\left(\mathrm{~mm}^{2}\right)$

$b:$ width of plate $(\mathrm{mm})$

$t:$ plate thickness $(\mathrm{mm})$

Reinforced concrete beam with the embedded steel truss shear design was calculated by assuming the shear force provided by steel truss was equal or close to the shear forces provided by the concrete, $V_{c}$, and the $V_{c}$ value was taken based on Equation 4. In this design, all of the specimens should be designed falling into shear failure by using minimal diameter and maximal spacing of transverse reinforcement. The design did not confirm the requirement according to SNI 2847:2013. Whereas the value of $V_{c}$ was taken by assuming $V_{c} \neq 0$, to make sure the effectiveness of embedded steel truss in plastic hinge area of the conventional beam.

\section{Research methodology}

\subsection{Material properties}

In this experimental study, two reinforced concrete cantilever beams were tested make it into shear failure. The specimens had a $900 \mathrm{~mm}$ clear span and a rectangular section of $170 \times 300 \mathrm{~mm}$ reinforced by 10 deformed bars of $16 \mathrm{~mm}$ in diameter with $25 \mathrm{~mm}$ clear cover. Two non- deformed bars with $8 \mathrm{~mm}$ and $4 \mathrm{~mm}$ in diameter were used as transverse reinforcement. The first one was spaced in every $50 \mathrm{~mm}$ above the plastic hinge zone and the second was spaced every $150 \mathrm{~mm}$ along the plastic hinge zone. The average of cylindrical compressive strength at the time of the test specimen was $f^{\prime} c=25.76 \mathrm{MPa}$. Table 1 shows the yield strength of the steel properties of the cantilever beam.

Table 1. The steel properties of the cantilever beam

\begin{tabular}{lc}
\hline \multicolumn{1}{c}{ Steel properties details } & $\begin{array}{c}\text { Yield strength, } f_{y} \\
(\mathrm{MPa})\end{array}$ \\
\hline $\begin{array}{l}\text { Flexural reinforcement }(\varnothing=16 \mathrm{~mm}) \\
\text { Transverse reinforcement }(\varnothing=4 \mathrm{~mm})\end{array}$ & 410.56 \\
in plastic hinge zone & 584.85 \\
$\begin{array}{l}\text { Transverse reinforcement }(\varnothing=8 \mathrm{~mm}) \\
\text { above plastic hinge zone }\end{array}$ & 370.76 \\
$\begin{array}{l}\text { Diagonal bar }(\varnothing=10 \mathrm{~mm}) \\
\text { Plate }(\mathrm{t}=3 \mathrm{~mm} \text { and } \mathrm{d}=50 \mathrm{~mm})\end{array}$ & 370.76 \\
\hline
\end{tabular}

\subsection{Test specimens}

Two reinforced concrete cantilever beams were conctructed to investigate their behavior under cyclic loading. One beam was a reinforced concrete beam without embedded steel truss as a conventional beam (BK-150) and it is shown in Figure 4 and the second beam was a conventional beam with embedded steel truss (BU150 ) as can be seen in Figure 5. The concept of a design for the reinforced concrete cantilever beam with steel truss was done by embedding two steel trusses (Figure 3 and 5) into a conventional beam.

(9)

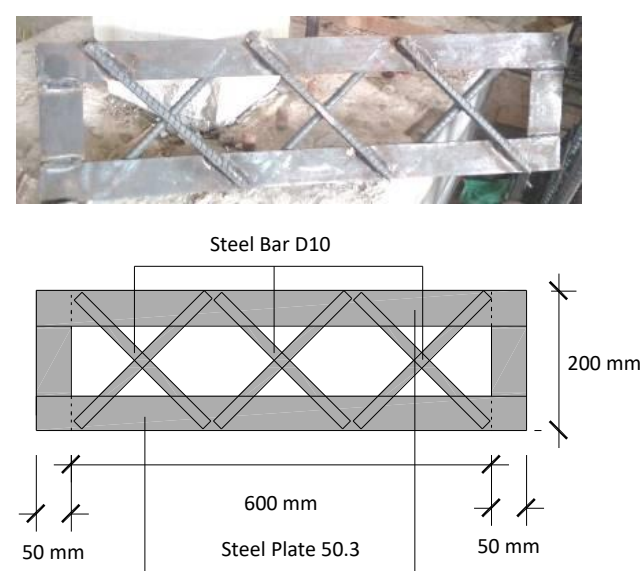

Fig. 3. Details of steel truss (test specimen BU-150) 


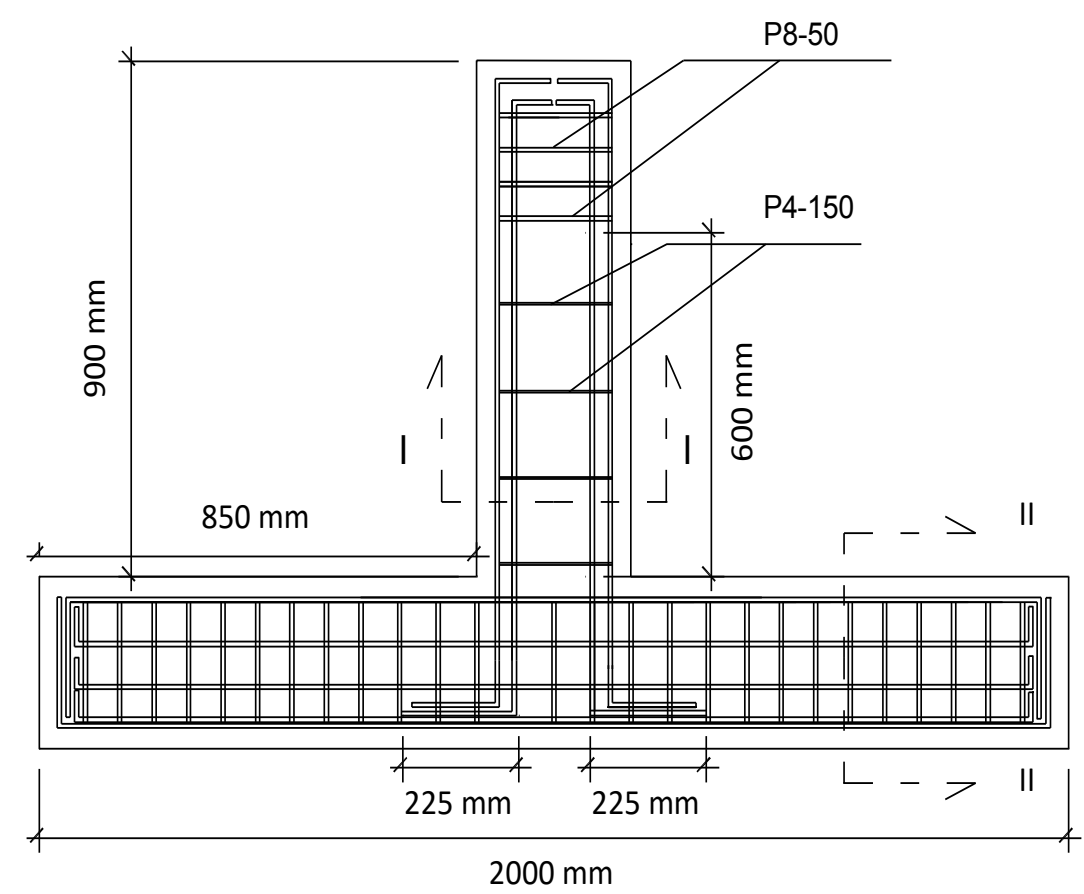

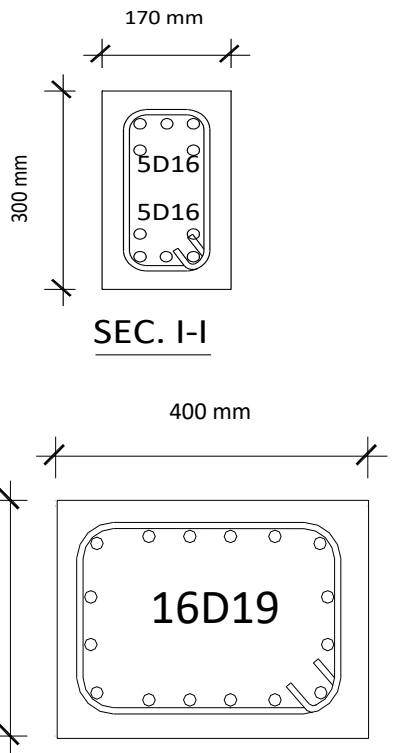

SEC. II-II

Fig. 4. Dimension details of test specimen BK-150

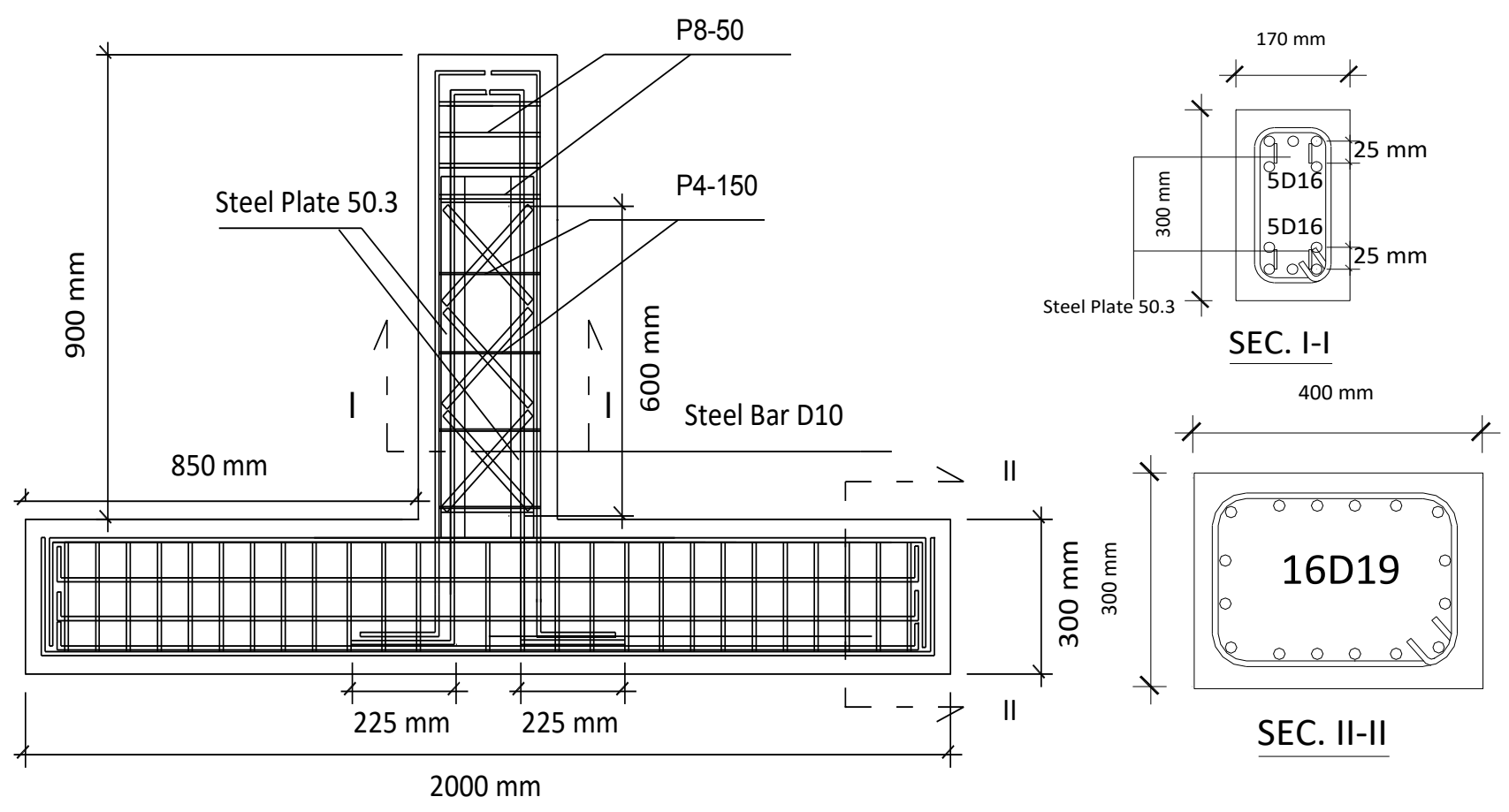

Fig. 5. Details of test specimen BU-150 
Based on the shear design in section 2.2, the calculation of the shear strength of cantilever beam with and without the embedded steel truss in the flexural plastic hinge of a beam is shown in Table 2 and 3. Where $V_{n}$ value was determined by $V_{c}+V_{s}+V_{d}$ in plastic hinge zone of beam only and $V_{u}$ was calculated using the flexural reinforcement moment capacity divided by the cantilever beam height.

Table 2. The shear strength of the specimens

\begin{tabular}{ccccccc}
\hline Specimen & $\begin{array}{c}V_{u} \\
(\mathrm{kN})\end{array}$ & $\begin{array}{c}V_{c} \\
(\mathrm{kN})\end{array}$ & $\begin{array}{c}s \\
(\mathrm{~mm})\end{array}$ & $\begin{array}{c}V_{s} \\
(\mathrm{kN})\end{array}$ & $\begin{array}{c}V_{d} \\
(\mathrm{kN})\end{array}$ & $\begin{array}{c}V_{2 d} \\
(\mathrm{kN})\end{array}$ \\
\hline BK-150 & \multirow{2}{*}{85.79} & 35.57 & \multirow{2}{*}{150} & 11.88 & $\mathrm{~N}$ & $\mathrm{~N}$ \\
\cline { 1 - 4 } & & & & & 19.27 & 38.54 \\
\hline
\end{tabular}

Table 3. The shear strength of the specimens (the continuation of Table 2)

\begin{tabular}{cccc}
\hline Specimen & $\begin{array}{c}V_{n}(\mathrm{kN}) \\
\left(V_{c}+V_{s}\right)\end{array}$ & $\begin{array}{c}V_{n 1}(\mathrm{kN}) \\
\left(V_{c}+V_{s}+V_{d}\right)\end{array}$ & $\begin{array}{c}V_{n 2}(\mathrm{kN}) \\
\left(V_{c}+V_{s}+V_{2 d}\right)\end{array}$ \\
\hline BK-150 & 47.45 & 47.45 & 47.45 \\
\hline BU-150 & 47.45 & 66.72 & 85.99 \\
\hline
\end{tabular}

The cantilever beams will be failed on the shear when the magnitude of the ultimate shear strength is greater than the magnitude of the nominal shear strength of the specimens.

\subsection{Test set up}

The experimental study was carried out in the Structure Laboratory, Department of Civil and Environmental Engineering, Faculty of Engineering, Universitas Gadjah Mada, Indonesia. The test equipment consisted of an actuator with the capacity of $\pm 100 \mathrm{kN}$ for horizontal loads up to $200 \mathrm{~mm}( \pm 100 \mathrm{~mm})$ displacements as shown in Figure 6. The specimens were tested according to ACI T11R-05 as can be seen in Figure 6, with the application of the reversed cyclic history of displacement with raised amplitude. The steps of each displacement can be seen in Figure 6 [1]. For each step, three complete cycles were campaign and three systems of data were that had been collected were used in this experimental studied : (1) three displacement transducers and a load cell attached to the hydraulic actuator; (2) the electrical resistance strain gauges were placed into the reinforcement elements as well as for the flexural reinforcement, transverse reinforcement, two diagonal bars and plate of steel truss at selected points; and (3) step by step photographic records of cracks propagation. A data logger for the data recording was used and all strain gauges were connected to it. The recorded data were taken at intervals of 10 second to ensure the comblete response historv.

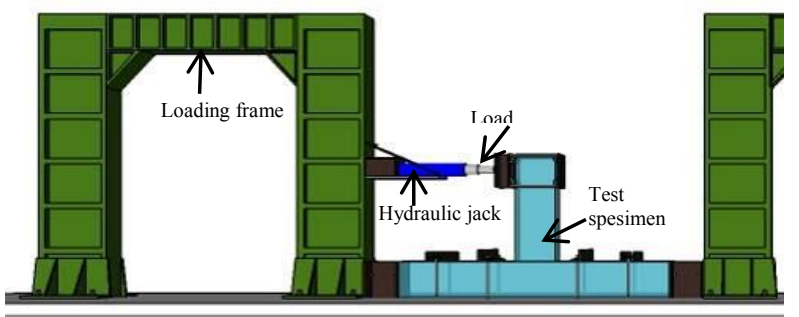

Fig. 6. The illustration of cyclic test set up arrangement

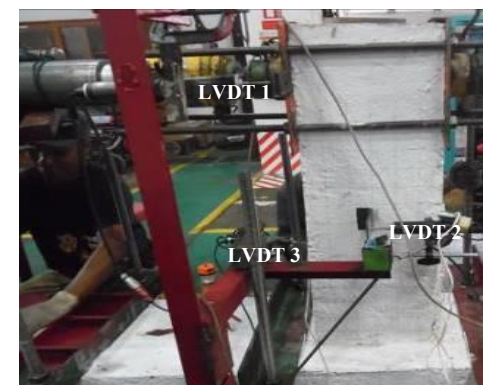

Fig. 7. The application of cyclic test set up arrangement

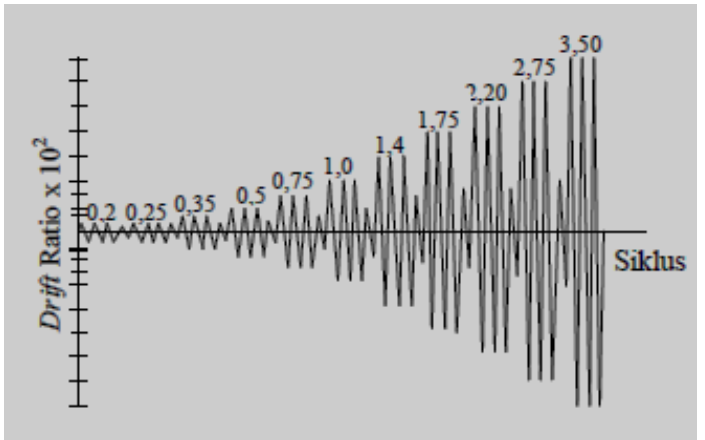

Fig. 8. Test sequence of displacement control cycles (ACI T1.1R-05) [1]

In the experimental study, the detailing of beam reinforcements, the five strain-gauges (SG) location and three displacement transducers (LVDT) that were used in the test shown in Figure 7 and 9 regarding to the plastic hinge regions of the beam.

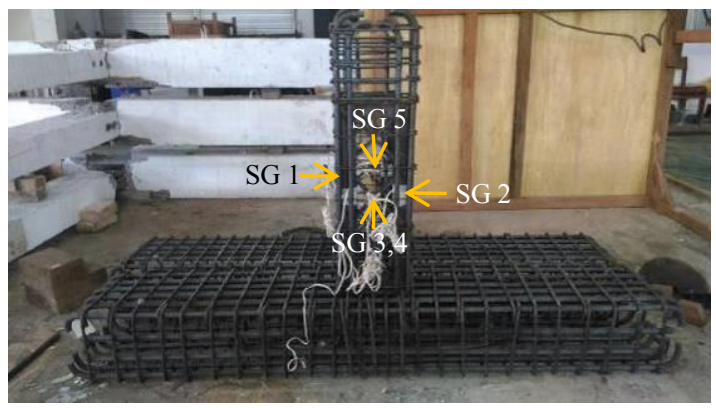

Fig. 9. The location of specimen strain gauges

\section{Result and discussion}

\subsection{Hysteretic response and load carrying capacity}

In order to compute the structural parameters of the reinforced concrete cantilever beams with and without embedded steel truss in the flexural plastic hinge, the specimens were subjected to cyclic loads that simulate seismic action, the hysteresis response curves drawn in Figure 10 and 11 from the tests were used to assess the ultimate strength and the ductility of the system. The shear load-displacement plot (hysteretic loops and backbone curve) for the test specimens are shown in Figure 10 to 12 respectively, and the displacement at peak load is shown in Table 4. 


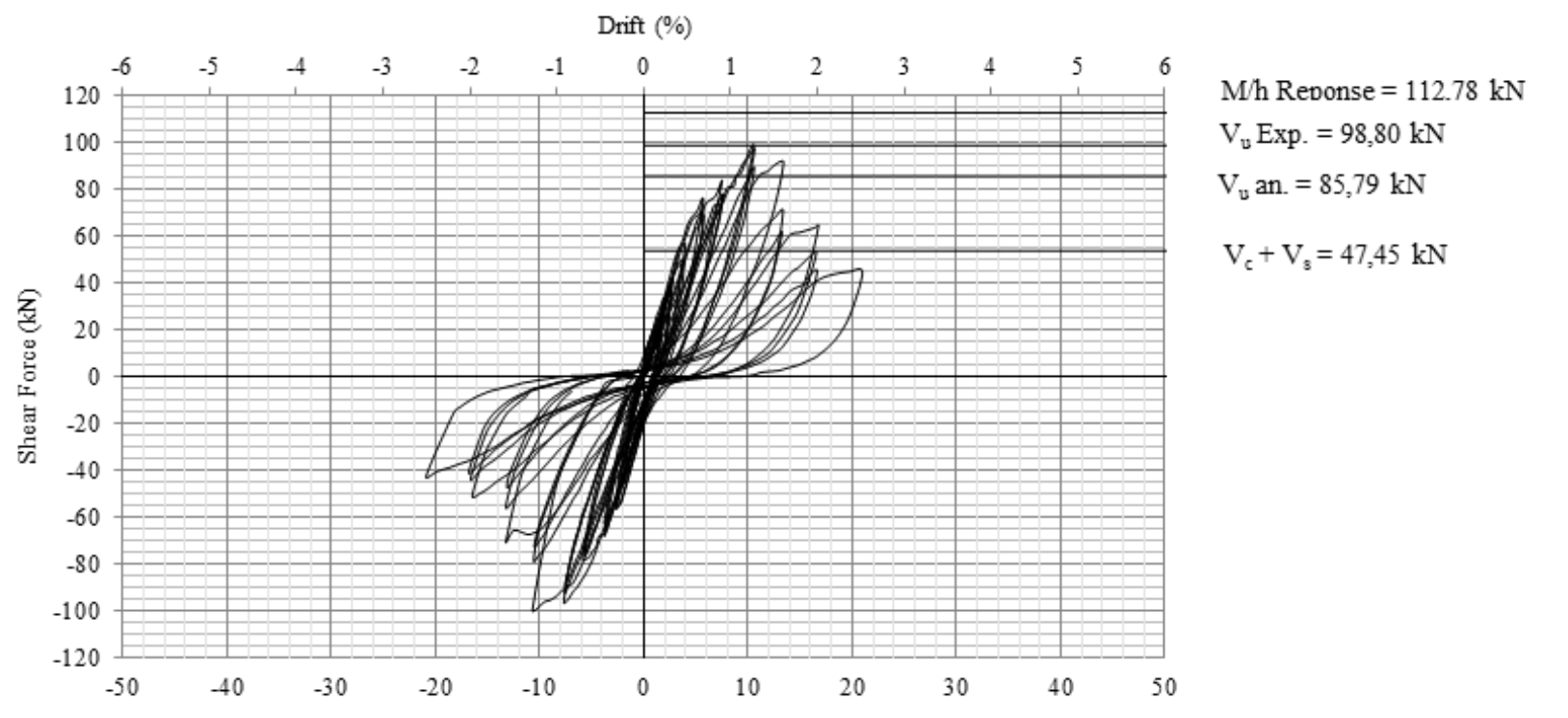

Fig. 10. Hysteretic response of test specimen BK-150

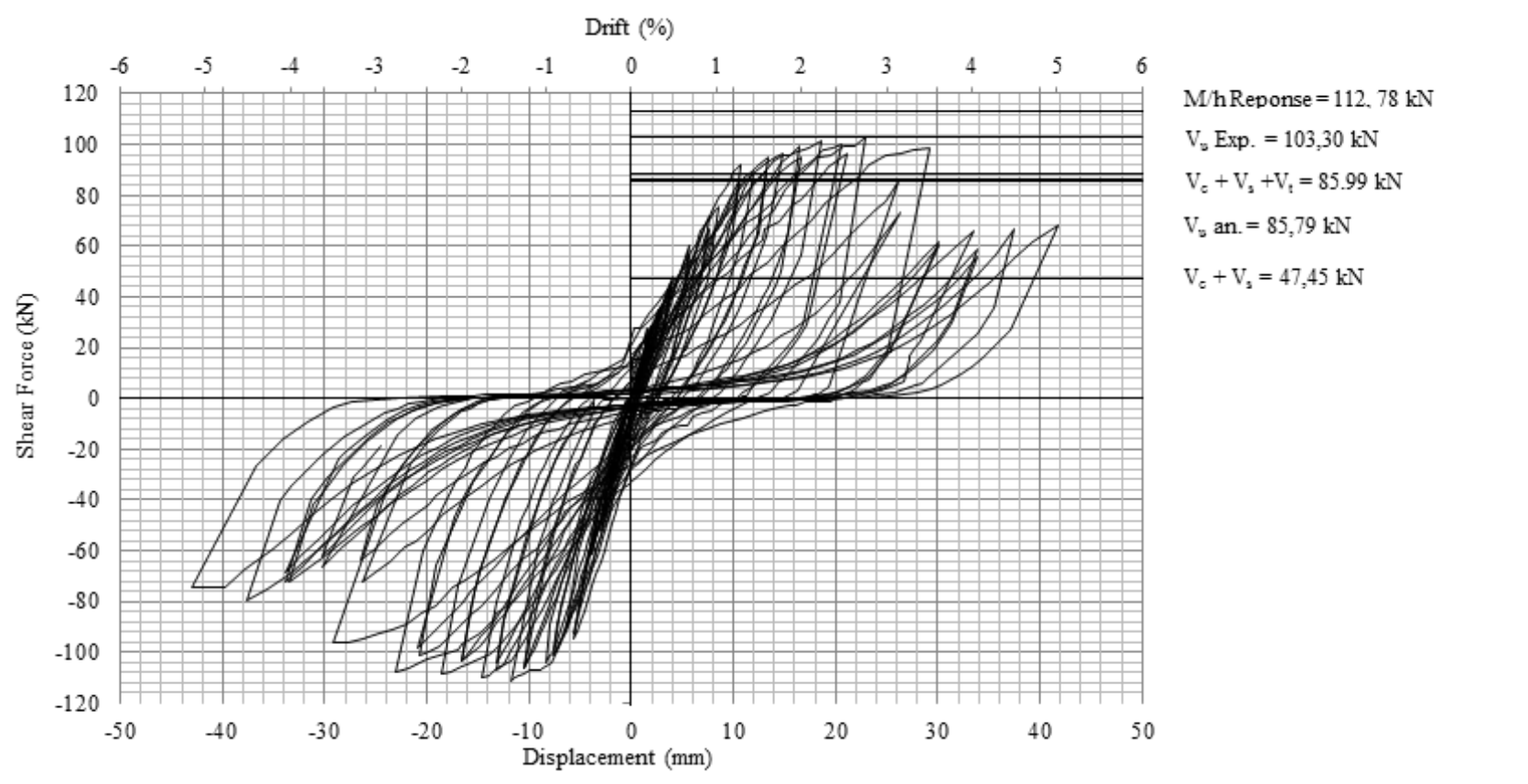

Fig. 11. Hysteretic response of test specimen BU-150

As seen in Figure 10 through 12, the ultimate load for BU-150 was taken $103.30 \mathrm{kN}$ higher than the ultimate load of BK-150 specimen but it was lower than $\mathrm{M} / \mathrm{hResponse}$. This value was qualified among these two values, $V_{n 1}$ and $V_{n 2}$ in Table 4. As shown in these figures and tables, when the result of the analysis is compared to the result in Table 5, it can be concluded that this system has an opportunity to be developed in the future. The embedment of two steel truss without welding has simplified labor working which makes it more efficient. Besides, it can increase the capacity of shear in the beam plastic hinge area significantly. However, it can increase the displacement ductility.

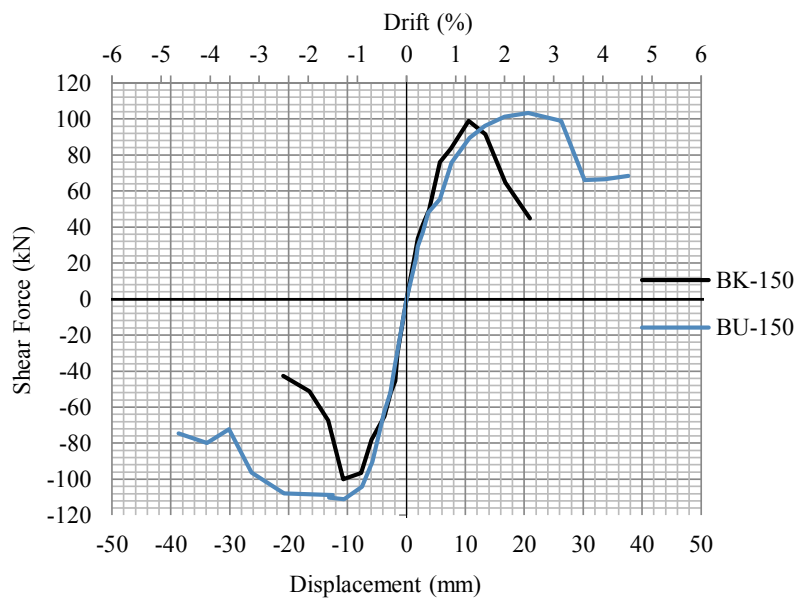

Fig. 12. The backbone curve of the test specimen 
Table 4. Displacement Vs Peak Load of the test specimen under cyclic loading

\begin{tabular}{ccccc}
\hline \multirow{2}{*}{ Specimen } & Peak Load & $\begin{array}{c}\text { Drift } \\
(\%)\end{array}$ & $\begin{array}{c}\text { Load } \\
(\mathrm{kN})\end{array}$ & $\begin{array}{c}\text { Displacement } \\
(\mathrm{mm})\end{array}$ \\
\hline \multirow{2}{*}{ BK-150 } & Positive peak load & 1.40 & 100.00 & 10.54 \\
& Negative peak load & 1.40 & 98.80 & 10.71 \\
\hline \multirow{2}{*}{ BU-150 } & Positive peak load & 2.75 & 103.30 & 20.69 \\
& Negative peak load & 1.40 & 111.10 & 10.60 \\
\hline
\end{tabular}

Table 5. The comparison of the analytical result and the test at the ultimate stage of the specimen (BU-150)

\begin{tabular}{ccccccccc}
\hline & \multicolumn{3}{c}{ Lateral Load (kN) } & \multicolumn{4}{c}{ Ratio of the shear strength } \\
\hline \multirow{2}{*}{ Test } & \multicolumn{3}{c}{ Analytical } & \multicolumn{4}{c}{ Test/Analytical } \\
\cline { 2 - 9 } & $\mathrm{V}_{\mathrm{u}}$ & $\mathrm{V}_{\mathrm{c}}+\mathrm{V}_{\mathrm{s}}$ & $\mathrm{V}_{\mathrm{n} 1}$ & $\mathrm{~V}_{\mathrm{n} 2}$ & $\mathrm{~V}_{\mathrm{u}}$ & $\mathrm{V}_{\mathrm{c}}+\mathrm{V}_{\mathrm{s}}$ & $\mathrm{V}_{\mathrm{n} 1}$ & $\mathrm{~V}_{\mathrm{n} 2}$ \\
\hline 103.3 & 85.8 & 47.6 & 66.7 & 86.0 & 1.20 & 2.17 & 1.55 & 1.20 \\
\hline
\end{tabular}

\subsection{Failure mode and crack pattern}

The cracks propagation was marked and the photographs were taken to show the distribution of the cracking pattern at specified levels of displacement. The crack pattern were marked, and the photographs were taken for these two specimens. The shear-flexure cracking was observed on two beams at all the drifts. At the third drift of $0.35 \%$, an initial flexure cracking was observed near the support structure in Figure 13, and at drift of $1.00 \%$, the significant diagonal cracking appeared in the middle of the beam as well as the plastic hinge zone (in $600 \mathrm{~mm}$ distance from the beam fix end). It is shown in Figure 14.

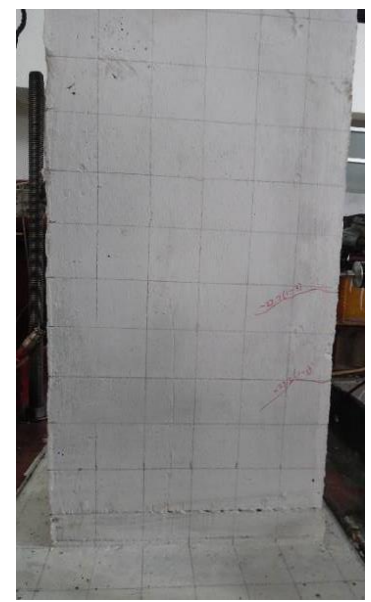

a. $\mathrm{BK}-150$

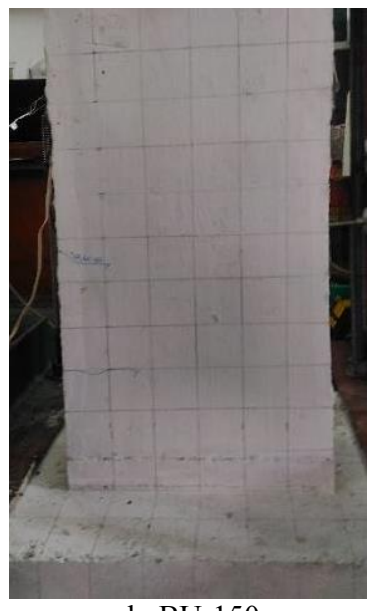

b. BU-150
Fig. 13. The crack patterns of the specimens at drift $0.35 \%$

Figure 14 through 16 shows the crack patterns in the middle observation at drift of $1 \%$ to $2.75 \%$ respectively, the entire of two beams and concentrated at the plastic hinge zone, the significant shear-flexure cracking that is widely occurred and increased immediately, indicating that the demand of shear in this area was higher than the other areas of the beam. When the beam reached its ultimate load, no more cracking occured on the beam, but the existing cracks got wider and deeper, especially in the plastic hinge region.

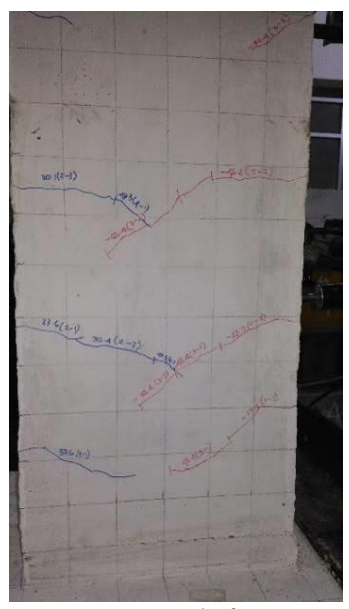

a. BK-150

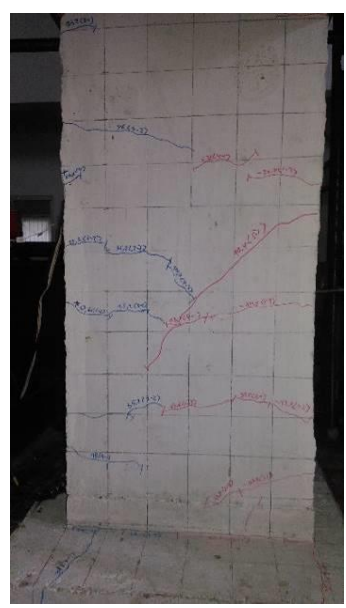

b. BU-150
Fig. 14. The crack patterns of the specimens at drift $1.00 \%$

Before the final drift for BK-150 specimen at drift of $2.75 \%$, as seen in Figure 16a compared to the other one in Figure 16b, the specimen without steel truss (BK-150) gets wider and it has deeper diagonal cracks than the specimen with embeded steel truss has in the flexural plastic hinge (BU-150). These results reveal that the embedment of steel truss in the flexural plastic hinge area of the beam can increase the shear capacity within this zone. However, the shear and moment interaction in the plastic hinge region makes an initial shear-flexure cracking occured in this zone immediately for the two specimens.

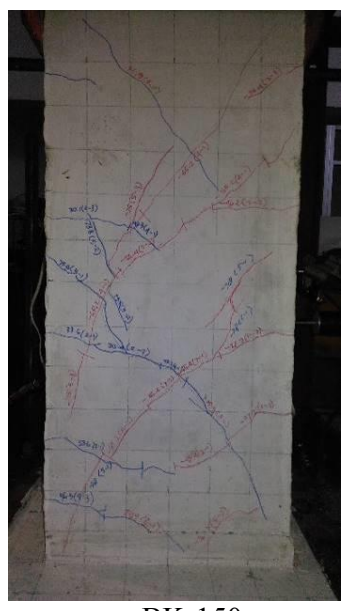

a. BK-150

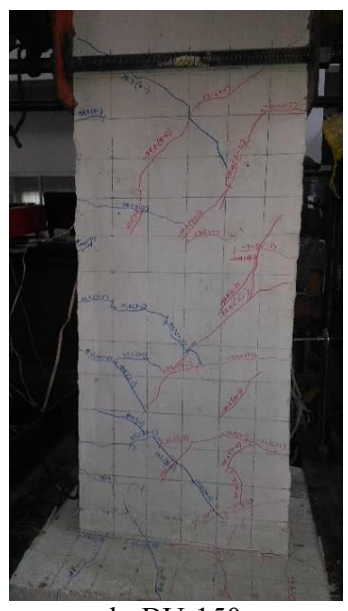

b. BU-150
Fig. 15. The crack patterns of specimens at drift $1.75 \%$

As can be seen from Figure 16 and 17, the specimen $\mathrm{BK}-150$ reaches its ultimate displacement at a drift of $2.75 \%$ that is lower than BU- 150 at a drift of $4.50 \%$. It can be concluded that the specimen with embedded steel truss in the flexural plastic hinge (BU-150) was more ductile than the specimen without steel truss (BK-150). The embedment of steel truss can change the inhibit of brittle shear failure, so itmaking this system having good potency for earthquake resistant member. 


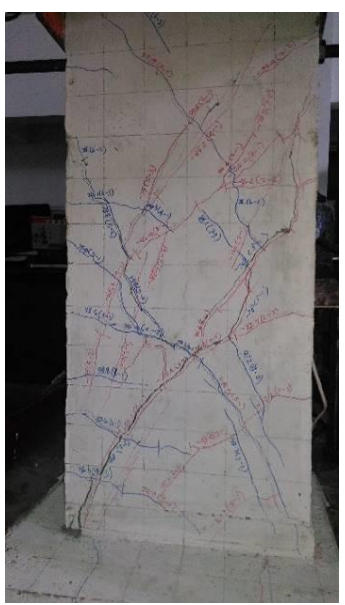

a. Drift $2.20 \%$

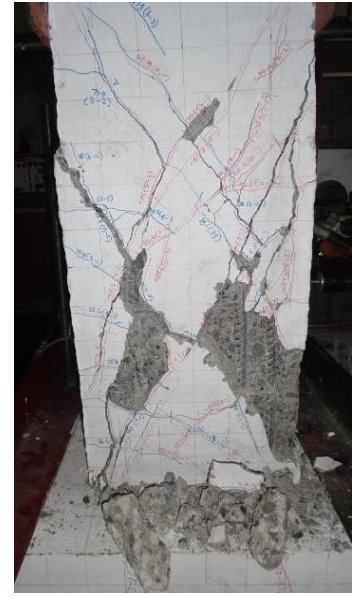

b. Drift $2.75 \%$
Fig. 16. The crack patterns of BK- 150 specimen

The existence of two steel trusses can increase the beam shear capacity in the flexural plastic hinge zone, while maintaining the shear capacity provided by the concrete core. However, the shear and moment interaction in plastic hinge zone of the beam makes an initial shearflexure cracking occured immediately in this zone.

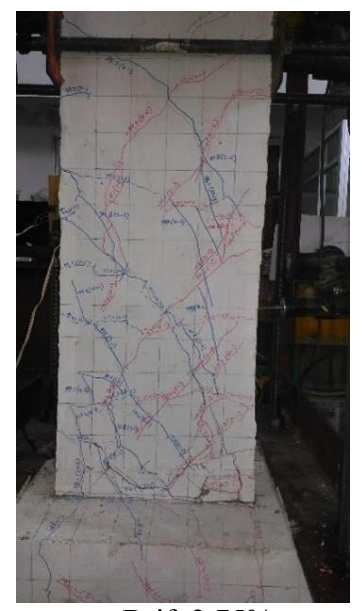

a. Drift $2.75 \%$

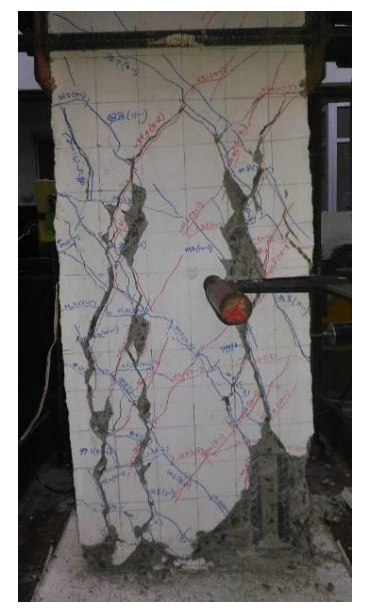

c. Drift $4,00 \%$

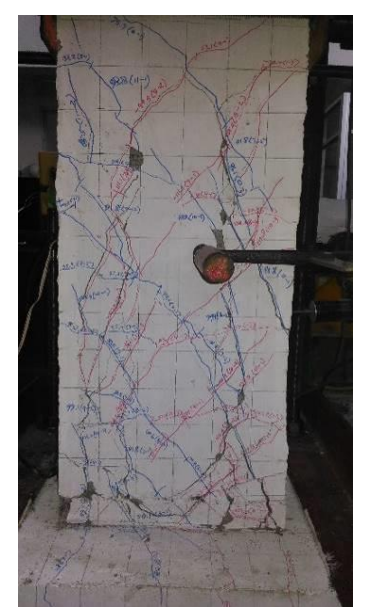

b. Drift $3.50 \%$

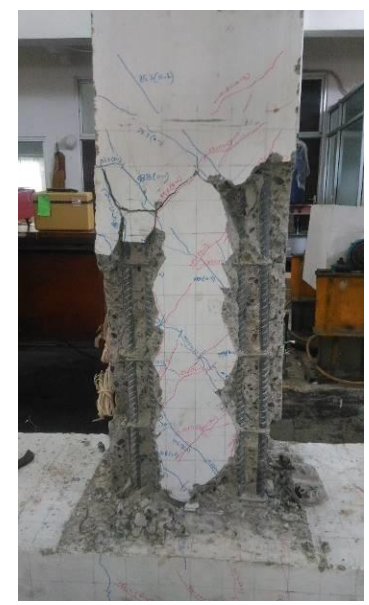

d. Drift $4,50 \%$
Fig. 17. The crack patterns of BU-150 specimen

\subsection{Stiffness}

The beam stiffness is defined as the angle of the relationship between load and deflection, whereas the value of stiffness is linear to the rigidity of structure elements. Figure 18 and 19 show the graphs of the specimen stiffness at initial drift for BK-150 and BU-150 in positive and negative directions of loading. As seen in this figure, the stiffness values were decreased together with the increase of drift ratio. This stiffness degradation may occur because of non-linear deformation of concrete, flexural and shear cracks of the beams, the slip of concrete and loss of concrete cover. From these figures, it can be seen that BU-150 specimen has a higher stiffness value than BK-150 in positive response at a drift of 1 to 5 . In addition, in the negative response, the stiffness value for BU-150 is higher than BK-150 after the drift of 1.5 , indicating that the embedded steel truss in reinforced concrete can raise the stiffness of the reinforced concrete beam as the conventional beam under cyclic loading.

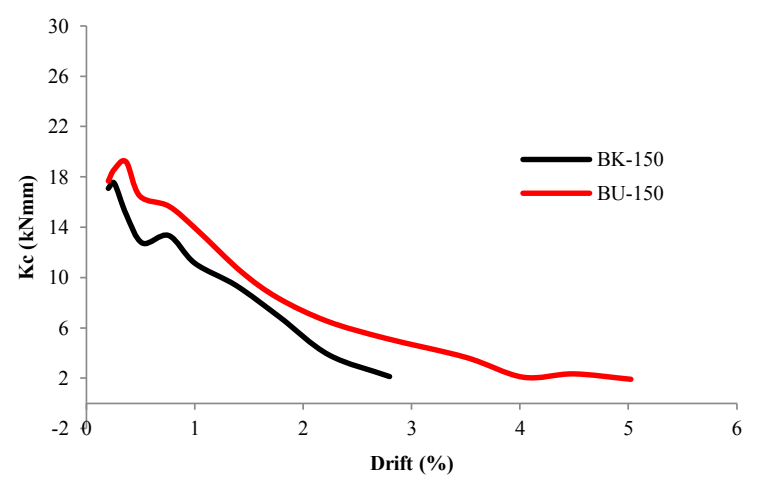

Fig. 18. The stiffness in positive response

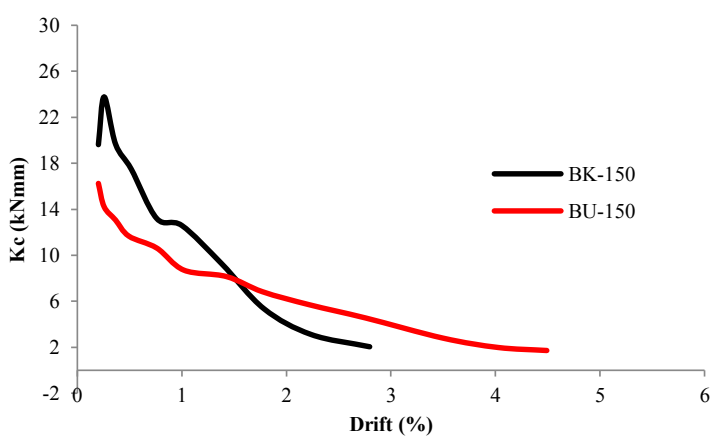

Fig. 19. The stiffness in negative response

\subsection{Equivalent viscous damping ratio (EVDR)}

The equivalent viscous damping ratio (EVDR) is defined as a displacement ductility function and a crucial parameter in the displacement application based method. The value of Equivalent Viscous Damping Ratio (EVDR) for each specimen is shown in Figure 20 and 21. As seen in Figure 20 and 21, EVDR of the test specimen with embedded steel truss (BU-150) is higher than the conventional beam (BK-150) that is also similar to the value of EVDR after the drift of 1.5 , in the positive response and after the drift of 2 in the negative response. 


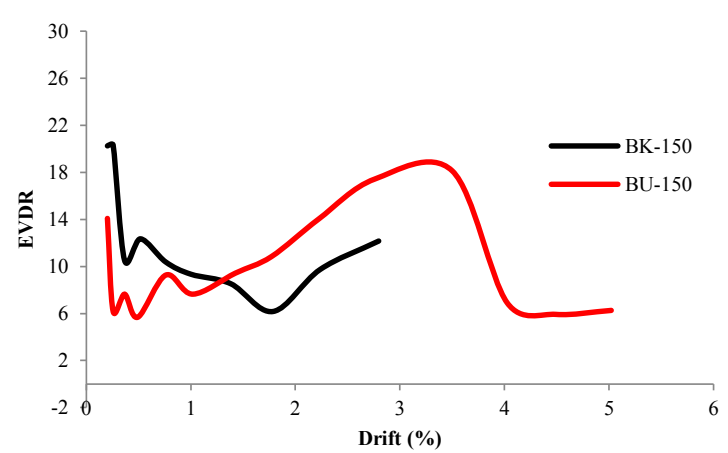

Fig. 20. EVDR in positive response

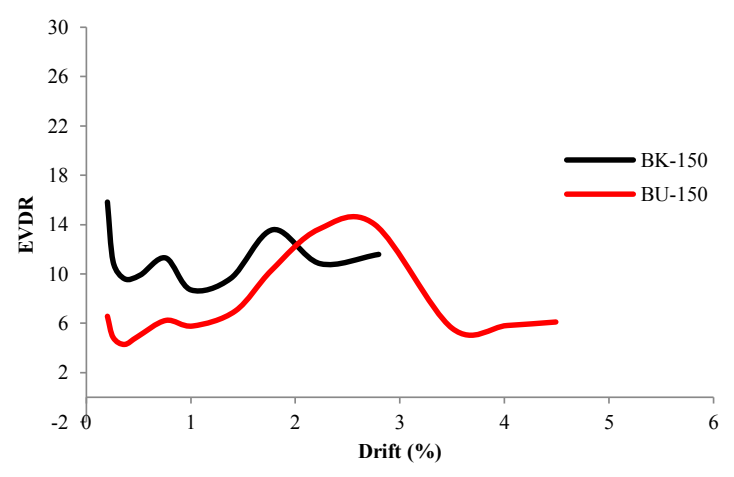

Fig. 21. EVDR in negative response

The EVDR value for specimen BU-150 was increased with an increase of drift ratio until the EVDR value reached its peak at a drift 3.5 in the positive response. Besides, in the negative response, the peak of EVDR value was reached at a drift of 2.5. These indicated that the damping capability of the specimen with an embedded steel truss in the flexural plastic hinge (BU-150) is better than the conventional beam (BK-150). It can be concluded that the specimen with an embedded steel truss suitable for seismic resistant structures.

\section{Conclusion}

Based on the limited experimental investigation which focuses on the inelastic behavior of the reinforced concrete cantilever beam with embedded steel truss in the flexural plastic hinge under cyclic loading, these are the conclusions that can be drawn:

1. The existence of a steel truss can raise the beam shear capacity in the flexural plastic hinge region and preserve the shear strength provided by the concrete for raising the energy dissipation capacity and the ductility of conventional reinforced concrete element. However, the shear and moment interaction in the plastic hinge region makes a minor shear-flexure crack immediately occurred in this region.

2. The elements design and detailing are significantly efficient and it becomes more simplified. The embedment of steel truss can force the beam into flexural failure and has better hysteretic behaviour than the one without the embedded steel truss and makes the system seems suitable for seismic resistant structures.
The author would express gratitude for the funding supported by Direktorat Jenderal Penguatan Riset dan Pengembangan, Kementerian Riset, Teknologi dan Pendidikan Tinggi, Republik Indonesia through Hibah Disertasi Doktor research program fiscal year 2018 .

\section{References}

1. ACI T1.1R-05. Commentary on Acceptance Criteria for Moment Frames Based on Structural Testing. , (2005)

2. NZSEE

AISBEGUIDELINES_Corr_06aAssessment and Improvement of the Structural Performance of Buildings in Earthquake., (2006).

3. SNI 2847:2013. Persyaratan Beton Struktural untuk Bangunan Gedung. BSN, Jakarta. (2013). [in Indonesian]

4. Park, R \& Paulay, T. Reinforced concrete structures. John Wiley and Sons Inc, New York. (1975).

5. Dhakal, R. P. \& Fenwick, R.C. Detailing of Plastic Hinges in Seismic Design of Concrete Structures. ACI Struct. J., 105(6), 105-S68. (2008).

6. Amir F. Shear Design of Reinforced Concrete Beam Using Steel Truss Encased in Flexural Plastic Hinge Zone. The $1^{\text {st }}$ of ICST Mataram University, Mataram University Press, Mataram, 1-2 December 2016, 3943. (2016).

7. Fenwick, R.C. Shear Deformation in Seismic Frame Structures. J. of Struc. Eng, ASCE, 109(4), 965-976. (1983).

8. Fenwick, R.C., Dely, R. \& Davidson, B.. Ductility Demand for Uni-Directional and Reversing Plastic Hinges in Ductile Moment Resisting Frames. Bulletin of The NZSEE., 32(1), 1-12. (1999)

9. Ichinose, T. A shear design equation for ductile R/C members. Earthquake Engineering \& Structural Dynamics, 21(3): 197-214. (1992)

10. Khuntia, M. \& Goel, S.C. FRC-Encased Steel Joist Composite Beams under Reversed Cyclic Loading. J. of Struc. Eng., ASCE, 124(10), 1115-1124. (1998)

11. Khuntia, M. \& Goel, S.C. Experimental study of FRC-encased steel joist composite beams. J. of Struc. Eng, ASCE, 125(5), 495-502. (1999).

12. Priestley, M.J.N., Verma, R., and Xiao, Y. Seismic shear strength of reinforced concrete columns. Journal of Structural Engineering, 120(8): 23102328. (1994)

13. Weng, C. C., Yen, S. I. N. and Chen, C.C. Shear strength of concrete-encased composite structural members. J. of Struc. Eng, ASCE, 127(10), 11901197. (2001).

14. Weng, C. C., Yen, S. I. N. and Chen, C.C.. Experimental study on shear splitting failure of fullscale composite concrete encased steel beams. J. of Struc. Eng. ASCE, 128(9), 1186-1194. (2002) 
15. Lam, W-Y., Su, R. K-I. and Pam, H-J. Experimental Study on Embedded Steel Plate Composite Coupling Beams. J. of Struc. Eng. ASCE, 131(8), 1294-1302. (2005). 